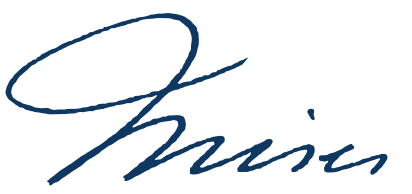

\title{
Os Fundamentos do Estado de Direito no Pensamento de F. A. Hayek
}

\author{
Anderson Barbosa Paz ID0000-0001-7799-3707 \\ Universidade Federal da Paraíba, João Pessoa, Paraíba, Brasil
}

Resumo: Nas décadas de 1960 e 1970, F. A. Hayek demonstrou, por meio de seus escritos, certa preocupação com o esvaziamento dos fundamentos da doutrina do Estado de Direito. Era necessário retomar e preservar os fundamentos dessa doutrina, a fim de assegurar a liberdade dos indivíduos face a seus pares e ao Estado. Parece que, hoje em dia, as sociedades livres passam por um processo similar de questionamento e relativização da doutrina do Estado de Direito. Os fundamentos do Estado de Direito defendidos por Hayek abrangem a liberdade individual e negativa, o evolucionismo social, e o império da lei aplicável de forma imparcial. O presente artigo visa a estudar os fundamentos da doutrina do Estado de Direito para F. A. Hayek. Em uma sociedade aberta tem-se um estado de liberdade em que todos podem usar seu conhecimento para seus próprios propósitos, limitados por normas gerais de aplicação universal. O Estado deve ser limitado por princípios gerais a que a comunidade tenha se comprometido prévia e constitucionalmente. Sem os fundamentos do Estado de Direito, como ensinou Hayek, têm-se a discricionariedade administrativa do Estado, a servidão da vontade e o racionalismo construtivista das normas.

Palavras-chave: F. A. Hayek, Estado de Direito, Império da Lei, Sociedade Livre, Liberdade Individual.

\footnotetext{
I Mestrando em Ciência Política e Relações Internacionais pela Universidade Federal da Paraíba. Bacharel em Direito pela Universidade Federal da Paraíba. Bacharel em LEA Negociações Internacionais pela Universidade Federal da Paraíba. Especialização em Direito Administrativo e Gestão Pública pela Faculdade Internacional da Paraíba (FPB). Formado em Teologia pelo Seminário Teológico Betel Brasileiro (curso livre). E-mail: andersonbarbosapaz@gmail.com
} 


\title{
The Fundamentals of the Rule of Law in F. A. Hayek's Thinking
}

\begin{abstract}
In the 1960s and 1970s, F. A. Hayek showed through his writings some concern about the emptying of the foundations of the rule of law doctrine. It was crucial to recover and preserve the foundations of this doctrine in order to guarantee the freedom of individuals before their peers and the State. It seems that, today, free societies go through a similar process of questioning and relativizing the the rule of law doctrine. The fundamentals of the rule of law defended by Hayek encompass individual and negative freedom, social evolutionism, and the empire of the applicable law in an impartial way. This article aims to study the fundamentals of the rule of law doctrine in F. A. Hayek. In an open society, a state of freedom can be enjoyed by everyone to use their knowledge for their own purposes, limited by universally applied general rules. The State must be limited by general principles to which the community has previously and constitutionally committed. Without the foundations of the rule of law, as Hayek taught, the administrative discretion of the State, the servitude of the will, and the constructivist rationalism of the norms rise.
\end{abstract}

Keywords: F. A. Hayek, Rule of Law, Law Empire, Free Society, Individual Freedom.

\section{Los Fundamentos del Estado de Derecho en El Pensamiento de F. A. Hayek}

Resumen: En las décadas de 1960 y 1970, F. A. Hayek demostró por medio de sus textos cierta preocupación con la anulación de los fundamentos de la doctrina del Estado de Derecho. Era necesario retomar y preservar los fundamentos de esta doctrina, con la finalidad de garantizar la libertad de los individuos frente a sus pares y al Estado. Parece que, hoy en día, las sociedades libres pasan por un proceso similar de cuestionamiento y relativización de la doctrina del Estado de Derecho. Los fundamentos del Estado de Derecho defendidos por Hayek abarcan la libertad individual y negativa, el evolucionismo social, y el imperio de la ley aplicable de forma imparcial. El presente artículo trata de estudiar los fundamentos de la doctrina del Estado de Derecho para F. A. Hayek. En una sociedad abierta se tiene un estado de libertad donde todos pueden usar el conocimiento para sus propios propósitos, limitados por normas generales de aplicación universal. El Estado debe ser limitado por principios generales a los que la comunidad se haya comprometido previa y constitucionalmente. Sin los fundamentos del Estado de Derecho, como enseñó Hayek, se tiene la discrecionalidad administrativa del Estado, la servidumbre de la voluntad y el racionalismo constructivista de las normas.

Palabras clave: F. A. Hayek, Estado de Derecho, Imperio de la Ley, Sociedad Libre, Libertad Individual. 


\section{Introdução}

A Segunda Guerra Mundial ainda não tinha acabado quando Friedrich August von Hayek (1899-1992) publicou seu clássico The Road to Serfdom (O Caminho da Servidão), em 1944. Sua obra antecipava aquilo que poderia resultar da ampliação do aparato estatal após o conflito mundial: diminuição da liberdade individual e servidão da vontade dos indivíduos ao Estado.

Alguns anos depois, o economista austríaco publicou, em 1960, sua obra The Constitution of Liberty (Os Fundamentos da Liberdade) em que demonstrava preocupação com o declínio da doutrina do Estado de Direito, essencial para a liberdade dos indivíduos. Nesse mesmo sentido, na década de 1970, Hayek publicou os três volumes de sua obra Law, Legislation and Liberty (Direito, Legislação e Liberdade). Nesse texto, o economista austríaco apresentou um pensamento desenvolvido sobre os fundamentos de uma ordem liberal que preserva o Estado de Direito.

As obras de F. A. Hayek, das décadas de 1960 e de 1970, demonstravam certo interesse na retomada da doutrina liberal do Estado de Direito que havia sido deturpada. Para o economista austríaco, era preciso que se repensasse e conservasse os fundamentos da doutrina do Estado de Direito para a preservação das liberdades individuais.

Parece que nos dias atuais, as sociedades ocidentais passam por um processo semelhante de esvaziamento da doutrina do Estado de Direito. Em geral, tanto os Parlamentos inflacionaram o Direito com uma alta produção de normas específicas, quanto os governos Executivos ampliaram o aparato burocrático da administração pública.

Nesse contexto, a tendência do Estado se ampliar através de normas específicas pode erodir os fundamentos do Estado de Direito. Tal caminho diminui a liberdade dos indivíduos, tornandoos suscetíveis à submissão à vontade governamental. Os fundamentos do Estado de Direito defendidos por Hayek sustentam a liberdade como ausência de coerção, o evolucionismo social, e a defesa do império da lei aplicável de modo imparcial. Sem esses princípios fundamentais, a liberdade cidadã não subsiste. A partir dessa problematização, o presente artigo visa a estudar os fundamentos da doutrina do Estado de Direito para F. A. Hayek.

\section{O Surgimento e o Declínio do Estado de Direito, Segundo F. A. Hayek}

De acordo com Hayek (1983), desde a Grécia Antiga, havia uma concepção ideal de isonomia que significava uma contraposição ao governo arbitrário dos tiranos. Aristóteles defendeu a aplicação imparcial da lei. Importada para a Inglaterra e Itália no século XVI, tal noção ganha conotações de um estado de leis gerais, aplicáveis igualmente a todos por magistrados imparciais. E continua tendo esse significado até o século XVII, quando é substituída pelas expressões igualdade perante a lei, governo da lei ou Estado de Direito.

Porém, explica o autor austríaco (1983), no fim do século XVIII, a influência dos romanistas substitui a tradição grega. Nos últimos anos do Império Romano, com o surgimento de aspirações igualitárias, a lei passara a ser um instrumento de política social pelo qual o Estado aumentava o controle sobre a economia. Após a queda desse Império, passou-se um milênio 
sem que a lei fosse tida como o meio para proteger a liberdade individual. Ainda assim, quando se redescobriu a necessidade de legislar, voltou-se não à tradição grega, mas sim à romana.

Segundo o economista austríaco (1983), com a morte de Elizabeth, rainha da Inglaterra no século XVI, abriu-se uma luta entre o soberano e o Parlamento. Este queria limitar aquele. No século XVII, sob a influência do liberalismo clássico de John Locke, buscou-se impedir a arbitrariedade do governo, independente de quem o exercesse, fosse o soberano, fosse o Parlamento. A noção de liberdade individual, com os contornos modernos, surgiu na Inglaterra no século XVII.

Nesse sentido, conforme Hayek (1983), quem detinha o poder deveria governar mediante leis pré-estabelecidas permanentemente, e não por medidas excepcionais. Juízes imparciais e íntegros deveriam decidir conforme as leis, como também empregar as forças internas da comunidade no cumprimento delas. Quando do século XVIII, ampliam-se os princípios alcançados pelos ingleses no século anterior. David Hume, Adam Smith, Blackstone, Edmund Burke, William Paley, dentre outros, defendem e sustentam o governo da lei, e formam uma doutrina de Estado de Direito.

Contudo, explica o escritor austríaco (1983), no fim do século XVIII, com a formulação de um novo liberalismo influenciado pelo racionalismo dos filósofos radicais da tradição francesa - Rousseau, os Fisiocratas e Condorcet -, os princípios da liberdade inglesa são revisados. $\mathrm{O}$ utilitarismo de Bentham insere na Inglaterra o desejo de reformular todo o aparato normativo e as instituições do país com base em princípios racionalistas e utilitaristas. O ideal francês de governo dos homens - em que uma vontade racional prescreve a lei garantidora de liberdade - substitui o império da lei nos moldes britânicos.

Para Hayek (1983), a tradição britânica firmava-se na jurisprudência do direito consuetudinário. A essência da liberdade está na espontaneidade e na ausência de coerção, que se dá por uma evolução lenta e parcialmente consciente. A origem das instituições advém da sobrevivência das mais funcionais para a sociedade. A moral, a linguagem, as instituições e o Direito evoluem por um processo de conhecimento cumulativo no qual a razão humana pode atuar com êxito.

Por outro lado, conforme Hayek (1983), na tradição Iluminista francesa, de característica racionalista, a liberdade só se realiza na busca de um propósito coletivo absoluto, estabelecido pela determinação doutrinária. Nessa tradição, a razão humana preexistente e independente cria as instituições e a sociedade civil através de um primeiro legislador sábio ou por um contrato social original. Essa tradição francesa origina a crença democrática racionalista.

Em suma, diz Hayek (1983) que pela tradição evolucionista britânica, a civilização é resultado de um processo de tentativa e erro, em que se acumulam experiências passadas de geração à geração. $\mathrm{O}$ mercado evolui através da harmonização de normas e princípios de interesses conflitantes e vantagens mediante concessão, de modo que o Estado limitado tem algumas funções na salvaguarda da ordem A perspectiva racionalista francesa afirma, por sua vez, que o homem, por meio de seus atributos morais e intelectuais, molda a civilização conforme um projeto prévio, nos termos de princípios racionalmente e artificialmente construídos. 
Sob a influência inglesa, explica o escritor austríaco (1983), a formação norte-americana importa os princípios e valores do Estado de Direito inglês. Contudo, quando os cidadãos da Nova Inglaterra percebem que a Constituição britânica tem pouca força face ao avanço do Parlamento, concluem que precisam construir os fundamentos que lhes faltam. Uma nova carta constitucional deve separar os poderes e limitar as atribuições das autoridades que só podem agir conforme os termos da lei. A Constituição se torna uma proteção do povo contra a arbitrariedade dos órgãos de governo.

De acordo com Hayek (1983), em solo americano formam-se os princípios gerais do texto constitucional. Em primeiro lugar, há limites à razão deliberada e se deve confiar nos princípios já comprovadamente consolidados. Além disso, a hierarquia das normas não termina necessariamente com os preceitos de direito constitucional explicitamente expressos, mas considera princípios implícitos que possibilitam o consenso e as leis fundamentais escritas. Ademais, nenhum indivíduo e nenhum grupo pode impor aos demais a lei conforme the convier. Logo, o poder é um clima de opinião a que as pessoas obedecem, devendo ser exercido conforme os princípios aceitos por todos e dispostos na Constituição.

Em consequência, nos Estados Unidos da América, estabeleceu-se que o Legislativo deveria se sujeitar a normas gerais, que deveria lidar com os problemas sociais emergentes de acordo com os princípios básicos dos casos precedentes, e que, se infringisse um princípio fundamental, ainda que implícito, deveria buscar constatar se as convicções básicas do povo realmente mudaram.

Conforme Hayek (1983), enquanto que em território norte-americano arranjavam-se novos contornos para uma emergente nação constitucional, na maioria dos países europeus, por volta do século XVII, as tradições de liberdade minguavam. A máquina burocrática administrativa diminuía a liberdade gradativamente. A Alemanha, diferente da França, não se permitiu acreditar na eficácia automática da democracia na limitação da arbitrariedade governamental. E criou uma elaborada teoria dos controles da administração com ampla influência.

A partir da filosofia da razão prática de Immanuel Kant, começou-se a formar uma teoria de Estado de Direito (Rechtsstaat). Hayek (1983) explica que a teoria da moral kantiana e seu conceito de imperativo categórico propõem que a garantia da liberdade individual se dê dentro do âmbito da lei geral aplicável a todos. Nesse mesmo sentido, Wilhelm Humboldt propaga a ideia de que a única função legítima do Estado é a aplicação da lei. A partir da influência prussiana, no começo do século XIX, desenvolve-se sistematicamente a noção teórica do Estado de Direito no contexto alemão.

Contudo, elucida Hayek (1983), é também na Prússia que, pelas décadas de 1870 e 1880, começou a ganhar força o movimento socialista rumo a um Estado intervencionista. Os poderes discricionários dos governos foram ampliados e o Estado de Direito foi reconfigurado. A discricionariedade do governo é expandida e diminui-se a força do império da lei. O Estado de Direito torna-se um Estado previdenciário.

Segundo Hayek (1983), as ideias políticas que embasam esse novo momento têm em comum a aversão à limitação da autoridade por meio de normas legais, ao passo que dispõem de uma disposição de conferir às forças do Estado mais poder para estruturar racionalmente 
as relações sociais segundo um ideal de justiça social. Já no século $\mathrm{XX}$, dentre os principais movimentos que contribui para essa nova configuração, destaca-se o positivismo jurídico.

Por essa doutrina, o direito é a norma posta, conforme a vontade humana. Conforme Hayek (1983), por uma concepção lógico-formal, exigem-se apenas que todas as ações do Estado sejam autorizadas pelo Legislativo. A lei se torna uma questão de mera legalidade. A doutrina do Estado de Direito é associada aquilo que é posta em termos formais pelo Estado. Logo, o Legislativo torna-se ilimitado. A Alemanha de Hitler, a Itália de Mussolini e o socialismo russo tornam-se legítimos Estados de Direito.

Apesar do surgimento da doutrina do Estado de Direito ter propiciado a limitação do Estado e a ampliação da liberdade dos indivíduos, com o tempo, tal doutrina assumiu outras características que desvirtuaram sua finalidade. Hayek se propõe a retomar e sublinhar os fundamentos do Estado de Direito para uma ordem de liberdade dos indivíduos.

\section{Liberdade e Coerção: O Papel do Estado}

Na definição de Hayek (1983), a liberdade individual é aquele estado no qual o homem não está sujeito à coerção, isto é, sujeito à vontade arbitrária de outrem. Uma política da liberdade deve minimizar a coerção ou seus efeitos negativos, ainda que não a elimine completamente. A liberdade é a possibilidade de determinar a própria conduta conforme as próprias pretensões. Dessa forma, a liberdade pressupõe uma esfera privada em que outros não podem interferir. Logo, a liberdade é ausência de coerção do homem pelo homem. Assim, a liberdade é negativa e individual. Seu oposto é a coerção.

Segundo Hayek (1983), a coerção pode ser delineada como o controle exercido sobre uma pessoa por outrem a ponto de, para evitar danos pessoais, aquela ser forçada a agir para atingir os objetivos do coator e não conforme suas próprias pretensões. A coerção anula o indivíduo enquanto ser que pensa e avalia, tornando-o um mero instrumento dos fins de outrem. $\mathrm{O}$ ato coercitivo implica a ameaça de infligir um mal e a intenção de provocar certa conduta. Mesmo que o coagido possa ter algumas opções de escolha, há uma redução de possibilidades de escolha determinadas por um terceiro que limita o arbítrio do indivíduo.

Para o economista austríaco (1983), quando os planos e opções são controlados por outrem, as ações são também controladas. A coerção é má, pois causa dano e submete uma pessoa a servir à vontade de outrem. A coerção só pode ser impedida se se garantir uma esfera privada que esteja protegida de uma intervenção externa. Porém, só há liberdade individual se houver algum grau de restrição do exercício da liberdade em uma sociedade.

Para garantir a liberdade a um número máximo de pessoas, postula Hayek (1983), o governo deve restringir uniformemente a liberdade de todos por meio de regras abstratas que impeçam a coerção arbitrária ou discriminatória de ou por outros indivíduos e evitem cada um de invadir a esfera de liberdade do outro. Tal obediência a regras abstratas comuns possibilita o campo para mais liberdade e diversidade.

De fato, explica o autor austríaco (1983), sociedades abertas atribuem o monopólio da coerção ao Estado, mas limitam seu poder a situações em que sua ação é necessária para 
impedir a coerção exercida pelos indivíduos. O Estado deve proteger a esfera privada contra a intervenção de outras pessoas por meio da criação de condições em que o indivíduo possa se determinar em sua própria esfera. As normas informam previamente qual será a ação do governo em diferentes situações.

Conforme Hayek (1983), a coerção do governo, nesse sentido, deve ser reduzida ao mínimo necessário através de normas gerais conhecidas, de modo que o agente não precise sofrer coerção, salvo caso se coloque em uma situação em que saiba que será coagido. Dessa maneira, a coerção impessoal e dependente de normas gerais abstratas faz com que os atos coercitivos do governo sejam transformados em dados pelos quais o agente pode pautar seus próprios planos. A coerção se torna uma ferramenta auxiliar ao indivíduo na busca de seus próprios objetivos e não um meio a ser usado para alcançar os objetivos de outrem. A lei previamente estabelecida, igualmente aplicável a todos os cidadãos possibilita que o indivíduo use seu conhecimento para alcançar seus objetivos.

A condição básica para a liberdade é o reconhecimento da propriedade privada individual, posto que só é possível agir conforme a própria determinação se houver o controle de alguns bens materiais. Para Hayek (1983), a posse da propriedade privada deve estar dispersa para que o indivíduo não dependa exclusivamente de determinadas pessoas para atender suas necessidades ou para empregá-lo. É por meio da concorrência que se dispersa a propriedade. Há liberdade em uma sociedade de livre mercado porque os indivíduos não permanecem sujeitos à vontade das pessoas de cujos serviços necessitam porque elas servem os seus clientes buscando o próprio interesse. Por outro lado, a liberdade se dá debaixo da lei que protege a individualidade e propriedade privada.

De acordo com o autor austríaco (1983), a liberdade na sociedade aberta implica responsabilidade. Os indivíduos devem ser capazes de uma ação racional, o que pressupõe a previsibilidade estabelecida em normas gerais das consequências de suas ações. As possibilidades de responsabilização devem ser sempre específicas e individuais. A responsabilidade do indivíduo alcança apenas aquilo que ele pode julgar, aquilo que suas ações podem considerar como consequências previsíveis, e aquelas ações próprias ou daquelas pessoas sob seus cuidados. Não pode existir uma responsabilidade coletiva de um grupo, a menos que se autodeclararem responsáveis.

Com efeito, diz Hayek (1985), as atividades coercitivas do ente estatal não constituem sua única função. Há atividades do governo não coercitivas ou de simples prestação de serviços financiadas por meios coercitivos - taxação -, e que são legítimas. O governo pode arrecadar fundos por meio de tributos para fornecer serviços que o mercado não pode prestar ou não pode fazê-lo adequadamente. A maioria das pessoas aceita tal compulsoriedade, visto que em troca lucram com contribuições semelhantes de outras pessoas que possibilitam a realização dos próprios objetivos.

Porém, ressalta Hayek (1985), a atividade estatal não implica concentrar serviços numa autoridade central, mas pode-se requerer a delegação de parte do encargo a autoridades locais e regionais. Aliás, por vezes, a melhor maneira de aproveitar tais recursos será o governo entregar a organização e administração desses serviços a empresas concorrentes entre si. 
Os gastos públicos previstos para tais serviços devem ser estabelecidos por uma norma predeterminada, a ser aprovada pelo eleitor que endossar a proposta por vias democráticas.

Para Hayek (1983), o governo pode ser responsável por leis sanitárias, o estabelecimento de padrões de pesos e medidas, restrições à venda de artigos perigosos, registro de terras, serviços de estatística, proteção contra epidemias, dentre outros, que auxiliem a escolha dos indivíduos. Ademais, o governo pode, de maneira excepcional, participar, como na construção de uma estrada, das atividades em que concorrem os agentes privados, desde que nas mesmas condições destes. O Estado também deve prover uma educação elementar para que se facilite a instrução básica para que os cidadãos compartilhem de suas crenças e princípios comuns, evitando o analfabetismo que impede o bom andamento da democracia.

Conforme o autor austríaco (1985), na proteção dos mais pobres, o governo pode agir em uma sociedade para garantir proteção contra sérias privações, por meio de uma renda mínima para evitar que os indivíduos caiam no extremo infortúnio social. Há muitos indivíduos que não têm com quem possam contar em caso de infortúnio, como os doentes, velhos, deficientes físicos ou mentais, as viúvas e os órfãos. O governo pode garantir legitimamente uma renda mínima para todos ou um piso abaixo do qual ninguém precisa descer, ainda que incapaz de se auto sustentar.

Segundo Hayek (1983; 2010), os valores da paz, da liberdade e da justiça são os únicos fundamentos imprescindíveis da civilização que cabem ao governo prover. A coerção só deve ser usada para fazer cumprir as normas universais de conduta justa e arrecadar recursos para manter alguns serviços prestados pelo ente governamental. O papel deste último é o de possibilitar a previsibilidade do exercício do poder coercitivo e a segurança jurídica dos atos individuais. O governo não deve anular os esforços individuais por meio de atos administrativos unilaterais. Além disso, o ente governamental deve dispor de uma estrutura legal que limite o mercado quando necessário, criando um ambiente propício a manutenção do livre mercado, declarando inválido todo acordo que restrinja a concorrência.

Em suma, no pensamento hayekiano (1983; 2010), o Estado estabelece alguns limites legais, mas o indivíduo decide livremente os fins que deve empreender sua vida e recursos, como também valora o que lhe é de maior ou menor importância. A liberdade só prevalece se for aceita como um princípio geral. Sua aplicação a casos particulares não requer justificativa alguma. O uso do conhecimento disperso acabará liberando mais forças para o bem do que para o mal. A política deve estar a serviço da sociedade. Seu papel é o de coordenar e facilitar as relações sociais. $\mathrm{O}$ âmbito político é instrumental, não normativo. A liberdade é produto de uma ordem espontânea.

\section{Kósmos: Uma Ordem Espontânea}

Segundo Hayek (1983), os princípios gerais que fundam e orientam uma sociedade livre derivam de um processo evolutivo social - uma ordem espontânea - que permite o descobrimento ou reconhecimento de normas. O indivíduo é ignorante quanto a vários aspectos da vida social e que nem todo conhecimento faz parte do intelecto humano. Logo, os hábitos, as emoções, 
as instituições, as tradições, a mente, o Direito, o livre mercado são adaptações à experiência passada que evoluíram pela eliminação seletiva da conduta menos adequada. À medida que evoluiu o conhecimento, acumularam-se condutas já testadas e adotadas. Desse processo resultam modelos que prevalecem. Portanto, o conhecimento do ser humano é limitado e consolidado por tradições e pela herança de uma evolução social.

Consequentemente, a ordem que resulta da evolução social é uma ordem espontânea. $\mathrm{O}$ autor austríaco (1985) explica que o grego clássico tinha palavras que possibilitavam diferenciar dois tipos de ordem. Taxis significava a ordem feita, racionalmente construída. Kósmos era a ordem resultante da evolução social. A primeira é uma ordem construída intencionalmente, podendo ser percebida pela observação e servir ao propósito de seu criador. A segunda é uma ordem espontânea abstrata e geral que só pode ser reconstruída na mente, sem um propósito específico, e pode se estender a circunstâncias tão complexas que mente alguma pode compreender completamente.

Para Hayek (1985), na ordem espontânea, é possível fixar linhas abstratas e gerais, mas não se pode especificar os pormenores, pois as circunstâncias são impossíveis de serem previamente conhecidas. É possível entender que há dois modos de considerar as atividades humanas. Pelo racionalismo construtivista, inspirado em René Descartes e predominante nos séculos XVI e XVII, afirma-se que as instituições humanas só servirão aos interesses humanos se tiverem sido intencionalmente criadas. Contudo, pelo racionalismo evolucionista ou racionalismo crítico, o indivíduo tem seu pensamento e ação orientados por normas que, "por um processo de seleção, evoluíram na sociedade em que ele vive e que, assim, são produto da experiência de gerações" (HAYEK, 1985, p. 6).

De acordo com o economista austríaco (1985), enquanto que a primeira perspectiva é pressupõe o conhecimento completo de todos os fatos relevantes, a segunda entende que a adaptação do agente se dá na apreensão de relações de causa e efeito a partir de normas adaptadas por circunstâncias desconhecidas, mas que determinam a configuração das ações bem-sucedidas. Hayek entende que o erro dos racionalistas construtivistas é de ilusão sinótica ao acreditar que todos os fatos relevantes são conhecíveis por alguma mente, podendo-se construir uma ordem social desejável. Porém, ninguém nasce dotado com uma mente que pode conceber a civilização e logo implantá-la.

Na interpretação hayekiana (1983; 1985), a mente humana é um sistema em constante mudança que resulta do esforço de adaptação ao ambiente. Ela se desenvolve em perene interação com as instituições que determinam a estrutura da vida social. Para evoluir, o agente deve permitir uma revisão contínua de suas concepções e ideias presentes à medida que novas experiências vão surgindo. Aprende-se por meio de práticas que deram bom resultado na manutenção da sobrevivência do grupo. Logo, todos os processos mentais têm um caráter abstrato - geral e não específico - para enfrentar uma realidade impossível de ser conhecida por completo.

A partir disso, Hayek (1985) postula que as normas de uma ordem espontânea são passíveis de serem descobertas. E podem ser aperfeiçoadas intencionalmente - pelo legislador ou juiz -, mas não determinadas racionalmente. Em um kósmos, a sociedade depende de que, 
após um processo de seleção, restem normas que tornem a vida social possível. Elas devem ser propícias à produção de uma ordem adaptada à multiplicidade de circunstâncias conhecidas pelos membros da sociedade. As ações dos indivíduos só precisam parecer entre si sob alguns aspectos abstratos para garantir a manutenção da ordem social.

Ainda assim, segundo Hayek (1985), algumas normas serão fruto de criação intencional, isto é, o governo deverá criar algumas normas para manter o kósmos. A ordem espontânea pode levar a um impasse que só pode ser corrigido rapidamente por uma norma intencionalmente criada. Ademais, o Direito pode se mostrar lento para se adaptar rapidamente a situações inteiramente novas. Essa criação intencional deve ser parcimoniosa, posto que o Direito de uma sociedade livre deve ser reformado à medida que princípios estabelecidos por decisões anteriores ou nelas implícitos são implicados a circunstâncias não anteriormente previstas.

Com efeito, segundo Hayek (1983), na ordem espontânea, o conhecimento pode evoluir por meio de normas genéricas expressas que podem ser transmitidas pela linguagem de uma a outra pessoa. O processo intelectual é apenas um processo de elaboração, seleção e eliminação de ideias já formadas. A razão humana deve apenas descobrir seus erros, não predizer ou moldar seu futuro, visto que o progresso não pode ser planejado. Do kósmos, florescem instituições complexas e ordenadas, voltadas para certos objetivos que não dependem do planejamento.

Para o autor austríaco (2017), é uma presunção fatal pensar que a capacidade de adquirir habilidades se origina da razão. A razão tem a finalidade de determinar os limites do seu próprio uso quando da reflexão sobre a ordem espontânea social. Porém, essa postura antirracionalista ou racionalista crítica não é irracionalista nem um apelo ao misticismo. Conforme o pensador austríaco (1983), não se deve abdicar da razão, mas sim examiná-la racionalmente em seus devidos limites, evitando torná-la onipotente, o que poderia destruí-la. É preciso conhecer racionalmente o funcionamento da vida social, antes de reformá-la. Ademais, a razão deve tender a uma construção gradativa e não global da sociedade, deve usar o material histórico disponível no momento, ao invés de recriar o todo.

Na leitura hayekiana (1985), as normas provenientes da ordem espontânea se tornam eficazes ao criarem uma ordem mesmo entre pessoas que não tem objetivo comum. O que os indivíduos precisam saber é como agir conforme as normas, mesmo sem saber expressá-las em palavras. E mesmo quando há mudanças normativas, cria-se uma situação em que haverá a probabilidade de se formarem expectativas corretas. O objetivo das normas deve ser o de possibilitar a harmonização das expectativas entre os indivíduos conforme as ações que têm sido regularmente repetidas na sociedade.

Para Hayek (1985), o Estado não pode aperfeiçoar os resultados por meio de determinações específicas. Da ordem espontânea resultam normas gerais que não permitem o governo violar a esfera privada. As medidas do governo devem ser examinadas em cada caso. O Estado deve proteger o funcionamento da catalaxia ou a ordem de mercado. Esta ordem serve à multiplicidade de fins distintos de todos os membros individuais. A catalaxia é a ordem derivada do mútuo ajustamento de muitas economias individuais em um mercado. É o tipo de ordem espontânea produzida pelo mercado por meio de ações de pessoas dentro das normas legais da propriedade, 
do contrato e da responsabilidade civil. Na catalaxia, cada indivíduo contribui na satisfação da necessidade alheia sem tomá-la em consideração ou sem tomar seus fins em consideração.

Em suma, Hayek (1983) defende que a liberdade significa que o que pode ser feito pelo indivíduo não depende de aprovação de autoridade alguma e só tem como limite as mesmas normas abstratas aplicáveis por igual a todos. O legislador, no ato de positivar a norma fruto de um processo espontâneo, deve reconhecer sua ignorância das circunstâncias especiais a que se aplicarão a norma. Ao fornecer dados inalteráveis para serem usados por quem fará os planos específicos, o legislador possibilita oportunidades, mas não certezas dos resultados. Essa ordem liberal depende do império da lei.

\section{Nomos: O Império da Lei}

Para uma sociedade livre, além da garantia da liberdade dos agentes privados e o conhecimento consagrado a partir de uma ordem espontânea, é preciso que a lei seja geral, abstrata e prévia, caracterizando o império da lei. Segundo Hayek (1985), há dois tipos de normas de conduta: nomos e thesis. A primeira é formada pelas normas gerais que derivam das condições de uma ordem espontânea e que não são cartesianamente criadas pelo homem, mas apenas descobertas. O nomos forma as leis. A lei constitui normas que governam a natureza e o comportamento humano. Por isso, sempre houve leis, antes mesmo de o indivíduo pensar em fazê-las. Elas eram observadas muito antes de serem verbalizadas e evoluíram ao formarem uma ordem das atividades do grupo como um todo.

O outro tipo de normas de conduta é a thesis. É formada pelas normas específicas, intencionalmente formuladas para atender a propósitos específicos, sendo invenções arbitrárias da mente planejadora do organizador. A thesis forma a legislação. Como exemplo, o direito do trabalho e o direito eleitoral. A thesis é criada pelo governo, enquanto a nomos é fruto de um processo de erros e acertos que ordenam uma sociedade livre.

Para Hayek (1985), a legislação é uma invenção relativamente recente na história humana. Tornou os homens mais poderosos e perigosos. Apesar de sua origem poder ser rastreada até a Grécia Antiga, a legislação perdeu força, porém ressurgiu no fim da Idade Média. A Europa ocidental passou quase mil anos sob a tradição da lei. O Direito era algo a se descobrir, não a fazer. Porém, com a redescoberta de $A$ Política de Aristóteles no século XIII, e a reinserção do Código de Justiniano no século $\mathrm{XV}$, as leis passaram a ser percebidas como dependentes da vontade humana. Progressivamente, "a legislação veio a ser lenta e gradualmente considerada um ato da vontade deliberada e irrestrita do governante" (HAYEK, 1985, p. 97).

Com efeito, segundo Hayek (1983; 1985), em uma sociedade aberta, o império da lei deve prevalecer. A lei, aplicada de forma isonômica, apenas delimita o campo de atuação individual. É uma norma geral fruto da ordem espontânea, procedente de hábitos inconscientes, de costumes e práticas correntes. A lei apenas oferece informação adicional que o agente deve levar em conta no seu processo decisório. A articulação das regras pertence a um estágio mais tardio da evolução em que a legislação aparece para descobrir, interpretar ou expressar o direito já existente. A elaboração de leis não deve ser dirigida por interesses particulares, 
mas deve estabelecer uma norma permanente e independente do efeito sobre determinados indivíduos ou grupos.

De acordo com Nogueira (2014), a sociedade aberta é aquela em que se combina kósmosnomos, isto é, ordem espontânea e normas gerais, resultando na ordem liberal de livre mercado e Estado de Direito. No outro espectro, tem-se a sociedade totalitária que combina taxis-thesis, a saber, uma ordem criada deliberadamente com normas específicas que comandam a ação dos indivíduos, resultando em uma legislação permeada de fins específicos. A legislação nem é igual para todos nem é fruto da ordem espontânea, e serve aos propósitos de quem a formulou.

Em uma sociedade aberta, explica Hayek (1985), há dois tipos de normas. A primeira é a norma de conduta justa que são aquelas normas que independem de fins e que servem à formação de uma ordem espontânea. Essas normas formam o nomos que é a base de uma sociedade com fulcro no direito privado. Há também as normas dependentes de fins que são aquelas que constituem o direito público, ou seja, determinam a organização do governo. São as normas originadas da thesis.

De acordo com Hayek (1985), para se preservar uma sociedade livre, só as normas de conduta justa, a saber, as normas do direito privado e do direito penal, devem ser obrigatórias e aplicáveis ao cidadão, devendo se limitar a informar qual é a livre esfera de ação para que o indivíduo faça suas escolhas. Tais normas tornam possível inferir, a partir dos fatos concretos, a quem pertencem coisas específicas. Elas devem tão somente evitar conflitos e facilitar a cooperação ao se eliminar certas fontes de incerteza.

Nessa esteira, para Hayek (1985), só ao se estender as normas de conduta justa a todas as relações entre os indivíduos e se privar de seu caráter compulsório aquelas não aplicáveis universalmente é que se pode se aproximar de uma ordem universal de paz, que pode integrar todos os indivíduos numa única sociedade. Os critérios para se saber se a norma se encaixa ou não no sistema jurídico é se ela pode se tornar aplicável universalmente e se é coerente com o resto do sistema jurídico.

Dessa formulação, deriva-se, conforme o autor austríaco (1985), que o direito privado proveniente do nomos possui normas de conduta justa, enquanto que o direito público originado pela thesis dispõe de normas organizacionais. Essas últimas quando impõem aos cidadãos obediência a ordenanças específicas que buscam alcançar propósitos específicos mitigam a amplitude da liberdade individual. Nesse cenário, entende Hayek (1983), o Poder Executivo, em sua ação coercitiva, deve ser limitado por normas que estabeleçam quando e onde pode ser usada a coerção, como também a maneira de se usá-la. Tais ações devem estar sujeitas à revisão judicial. Toda vez que a ação administrativa interferir no âmbito privado do indivíduo, os tribunais devem revisar a decisão administrativa.

Para o economista austríaco (1983), as normas guardam o universo da atuação do indivíduo, mas as decisões cabem exclusivamente a ele. Nas relações com os semelhantes, as normas devem ser inteiramente negativas, salvo se o indivíduo criar condições para o aparecimento de obrigações positivas. Além disso, as normas jurídicas devem ser instrumentais, isto é, são meios para que o indivíduo, junto com suas informações das circunstâncias, fundamente suas decisões. Com o conhecimento de causa e efeito pode fazer o que lhe aprouver. 
Em geral, explica Hayek (1983), as normas gerais e abstratas são medidas de longo prazo e devem referir-se a casos ainda desconhecidos, não sendo específica a determinadas pessoas, lugares ou objetos. A norma significa uma tendência a agir conforme determinada prática ou costume. São aprendidas por imitação de ações específicas, que o indivíduo repete por analogia. Ademais, as leis devem ser conhecidas, claras e mutáveis. Devem, também, ser igual para todos, podendo, inclusive, criar cláusulas diferentes para determinadas classes de pessoas, desde que não prejudique ou beneficie previsivelmente indivíduos conhecidos.

O império da lei, segundo Hayek (1985), deve impedir que as ações de diferentes indivíduos interfiram umas nas outras. Para tanto, deve estabelecer uma ordem legal em que a ação do indivíduo se orienta por uma previsão eficaz, podendo os agentes usar seus conhecimentos e prever que tipo de colaboração é possível aguardar dos outros. O Estado de Direito tem por objeto inúmeros propósitos diferentes de uma ampla gama de indivíduos. Para isso, as normas devem ser abstratas, gerais, conhecidas previamente, iguais para todos, não retroativas e estabelecidas por um longo período de tempo.

\section{Considerações Finais}

De acordo com Hayek, há pelo menos três bases fundamentais para a Constituição de uma sociedade livre. A primeira é que a liberdade individual de autodeterminação deve ser protegida da coerção de terceiros e do Estado. Uma sociedade livre não permite a servidão dos indivíduos ao ente estatal.

Em segundo lugar, uma sociedade livre não deriva suas normas e princípios de uma orientação construtivista e racionalista. Por influência da tradição britânica e norte-americana, Hayek defende que, como o conhecimento humano é disperso em normas, tradições, princípios não racionalizados, é preciso que uma sociedade aberta derive suas normas daquilo que permaneceu por ser acertado no passado. Isso, porém, não implica que não sejam necessárias reformas, mas sim que estas são feitas paulatinamente face a cada questão específica.

Em terceiro lugar, é fundamental que uma sociedade livre seja regida pelo império da lei. Normas de conduta gerais, prévias, abstratas e universais possibilitam a imparcialidade das ações dos indivíduos entre si, e do Estado para com os agentes privados. A lei, dessa forma, torna-se um dado, um ativo, para que o indivíduo faça suas escolhas individuais, tanto respeitando a vontade de outros, quanto tendo seu direito respeitado.

Uma Grande Sociedade pressupõe, portanto, que uma ordem espontânea resulte no governo das normas gerais, a fim de preservar a liberdade individual, a propriedade privada e o Direito da intervenção da legislação governamental artificialmente criada. Esses são os fundamentos que possibilitam, segundo Hayek, o estabelecimento e a manutenção do Estado de Direito em uma sociedade livre.

Hayek se preocupava em resgatar os princípios fundamentais para uma sociedade livre, posto que, sem um Estado de Direito, restam a discricionariedade administrativa do governo, a servidão da vontade e o racionalismo construtivista das normas. Sua preocupação não é datada 
ou restrita a certo momento da história. As sociedades livres hodiernas precisam resgatar e respeitar os fundamentos do Estado de Direito, não os deixando ao capricho do varejo político.

\section{Referências}

HAYEK. F. A. Os fundamentos da liberdade. São Paulo, Visão, 1983.

. Direito, legislação e liberdade: uma nova formulação dos princípios liberais de justiça e economia política. São Paulo: Visão, 1985.

. O caminho da servidão. São Paulo: Instituto Ludwig von Mises Brasil, 2010.

. Os erros fatais do socialismo. Barueri: Faro Editorial, 2017.

NOGUEIRA, Jorge Henrique de Saules. O Direito como Salvaguarda da Liberdade: elementos da Teoria do Direito de F. A. Hayek. MISES: Revista Interdisciplinar de Filosofia, Direito e Economia, v. 2, n. 2 (Edição 4), 2014.

RECEBIDO: 24 DE MAIO 2020

APROVADO: 12 DE JUNHO 2020 